\title{
O Caráter Essencial dos Corpos Homogêneos em Aristóteles
}

\author{
Rodrigo Romão de Carvalho
}

The present paper aims at examining the characteristics that determine the essential nature of the homogeneous bodies in Aristotle, from an analysis of Meteorology IV.12, which would at the same time establish a certain relationship with other treatises of natural philosophy and also in particular with books VII and VIII of Metaphysics. With this investigation, I will delineate a certain line of argument that goes against a reading perspective considered as traditional, with certain interpretive variants, according to which Aristotle would have adopted the idea of a universal teleology, in the general sense that all natural bodies would be generated for a specific goal, or for a natural purpose. According to a certain view, linked to this perspective, the teleological character of functional type of vital activities, notably expressed by the compositional arrangement of the non-homogeneous parts in the living being's complexion, would be somehow involved in the constitution of the homogeneous bodies considered in themselves and for themselves. In contrast to such a view, I will examine, in a precise way, to what extent the homogeneous bodies would comprise a certain formal factor directly involved in the characterization of their constitutional particularities, taking into account a comparative examination with other kinds of natural compositions, namely, elemental aggregates and living organisms. Thus, through this examination, I will explore the question of whether, in function of this formal factor, such bodies could present some teleological character trait, distinct from the functional type, characteristic of organic-animate constitutions.

De acordo com alguns estudiosos da filosofia natural aristotélica, Meteorológicos IV apresentar-se-ia como uma ponte entre os tratados acerca dos corpos inanimados e os tratados relativos à investigação dos organismos vivos (Furley, D. J., 1983, Gill, M. L., 1997, p. 154; 2014, pp. 335-336; Lennox, J. G., 2014, p. 292). Segundo Gill, o capítulo 12 (o último capítulo) do Livro IV dos Meteorológicos corresponderia ao principal texto por meio do qual seria sustentada a tradicional visão de que Aristóteles defendia a ideia de uma teleologia universal, ou seja, a ideia de que tudo no cosmos, incluindo os quatro elementos: fogo, ar, terra e água, viriam a ser em função de um fim ou de algum bem que eles, essencialmente, serviriam (335). 
Esta visão, atribuída a Aristóteles, de que ele estaria comprometido com a ideia de uma teleologia universal poderia ser constatada, por exemplo, no livro Space, Time, Matter and Form: Essays on Aristotle's Physics de David Bostock (2006, pp. 70-75), no qual o autor considera que o fator teleológico-funcional, característicos das atividades vitais, com base em certo trecho dos Meteorológicos IV.12, estaria também de algum modo não muito claro presente nos corpos homogêneos inanimados, como os minerais e os metais de um modo geral (73-74).

David Bostock considera que o fator teleológico-funcional das atividades anímicas, claramente apresentado pelo conjunto articulado das partes não homogêneas (por exemplo: coração, pulmões, braços etc.) na constituição orgânica, com base em uma passagem do capítulo 12 do livro IV dos Meteorológicos (390a14-20), que, de acordo com ele, tem sido "geralmente dada pouca atenção" (71), estaria também de algum modo, por analogia com os compostos orgânicos, presente nas composições homogêneas inanimadas. Contudo, como é observado pelo próprio autor, Aristóteles não fornece qualquer indício sobre quais seriam os fins inerentes a essas composições, no sentido de servirem a algum propósito natural (p.74). ${ }^{1}$

\footnotetext{
${ }^{1}$ Dentre aqueles que sustentariam a ideia de um único sentido de teleologia, ou seja, uma teleologia universal relacionada a propósitos naturais, de acordo com a interpretação tradicional, além de Bostock, poder-se-ia citar como exemplo também (i) Joseph Owens, o qual defende que Aristóteles procurou desenvolver a concepção de uma escala natural teleológico-gradativa, na qual os corpos inanimados existiriam para o bem das plantas, as plantas para o bem dos animais, e todos estes para o bem do homem (Owens, J., 1968, p 168). Neste caso, Owens teria como único suporte textual, para sustentar a sua tese, certa passagem do Livro I da Política, na qual Aristóteles escreve o seguinte: "As plantas existem para os animais, e os demais animais para o homem: os domésticos para seu serviço e alimentação; os selvagens, senão todos, ao menos a maior parte, com vistas ao alimento e outras ajudas, para proporcionar vestimentas e diversos instrumentos. Se, portanto, a natureza não faz nada imperfeito ou em vão, necessariamente produziu todos estes seres em vista do homem" (Política, I.8, 1256b15-22). Por outro lado, textos como os da Metafísica e, de um modo geral, os dos tratados de filosofia natural, indicam que os seres naturais não viriam a ser em vista de outra coisa, no sentido de serem em vista de resultados extrínsecos às suas próprias características essenciais. Por exemplo, em Metafísica (VI.10, 1035b23-25), Aristóteles afirma que as partes dos animais vêm a ser em vista da efetividade do todo substancial,

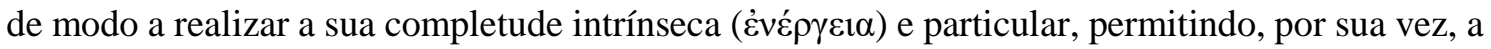

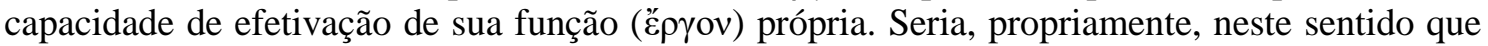
Aristóteles, em Física (II.7,198b8-9), irá dizer, então, que o fim se realizaria exclusivamente em vista da essência própria de cada tipo de ser. Sendo assim, penso que a passagem da Política, acima referida, deveria ser entendida tão somente no contexto particular em que está inserida. Além disto, poderíamos, ainda, mencionar a concepção de (ii) Francisco J. Ayala, mais próximo à linha interpretativa de Bostock, que acusou Aristóteles de estender para o domínio do inanimado as mesmas noções de caráter teleológicas, típicas das explicações empregadas no campo biológico (Ayala, F. J., 1970, p.15).
} 
Just as the goal of each animal is fully to realize its own form, independently of the purposes of other animals, and similarly (I suggest) with plants, so too we should recognize that even inanimate matter has goals of its own. There are many goals in nature. Seeing that the organic compounds formed from the elements can very clearly be assigned goals too (derived from their contribution to the animals - and plants? - formed from them), Aristotle is led to extend the hypothesis to inorganic compounds, such as bronze and silver, as well. So far as I am aware, he never makes any suggestion as to what these goals might be. He may conceive them, by analogy with organic compounds. (Bostock, 2006, pp.73-74).

Em desacordo com Bostock neste ponto, penso que Aristóteles não fornece algum indício sobre os referidos fins dos compostos inanimados, justamente porque tais compostos são caracterizados enquanto tais não por certas faculdades funcionais ${ }^{2}$ de qualquer natureza, como é caso das substâncias orgânicas constituídas por um conjunto inter-relacionado de partes não homogêneas, mas por certas qualidades ou afecções próprias:

As partes se distinguem, umas, por uma faculdade, outras, por suas qualidades: as partes não homogêneas, por serem capazes de realizar certas ações, por exemplo, a língua e a mão; e, as homogêneas, pela dureza, pela brandura e outras qualidades semelhantes (Geração dos Animais, I.18, 722b30-33). ${ }^{3,4}$

Assim, pois todas as coisas particulares deste tipo podem gerar-se por meio do calor, do frio e pelos movimentos por eles produzidos, solidificam-se com o calor e o frio: me refiro a todos os [sc. corpos] homogêneos, como a carne, o osso, o cabelo, o nervo, e todos os similares; de fato, todos se distinguem pelas diferenças mencionadas: a tensão, o estiramento, a fragmentação, a dureza, a brandura e todas as demais deste tipo; estas surgem pelo calor, pelo frio e de seus movimentos combinados. Por outro lado, ninguém pensaria o mesmo quanto aos [sc. corpos] não homogêneos, compostos daqueles [sc. dos corpos homogêneos], como a cabeça, a mão ou o pé (Meteorológicos, IV.12, 390b2-11). ${ }^{5}$

${ }^{2}$ Se há algum tipo de "propósito" relativamente às atividades do organismo vivo como, por exemplo, é necessário que os animais tenham o coração a fim de que haja uma fonte e uma "residência" do calor vital (Parva Naturalia, 469b10-15; Partes dos Animais, III.7, 670a23-26),


qualquer tipo de conscientização ou discernimento, tal como ocorre nas operações envolvidas nos procedimentos técnicos, pois como Aristóteles declara em Física II.8, 199b26-28: ö́o


não vem a ser em vista de algo, quando não se percebe que o que move tenha deliberado").

${ }^{3}$ Com relação às citações das obras de Aristóteles traduzidas para o português, utilizei a edição "Bekker I-II", as traduções para o inglês das edições bilíngues da "Loeb Classical Library", as traduções para o espanhol das edições "Gredos", bem como as traduções de Lucas Angioni dos Livros I e II da Física, e o Livro I das Partes dos Animais.

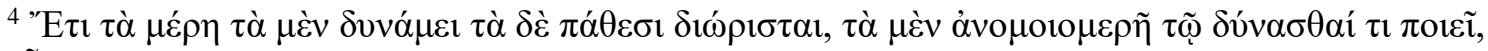


$\pi \alpha ́ \theta \varepsilon \sigma \mathrm{v}$.



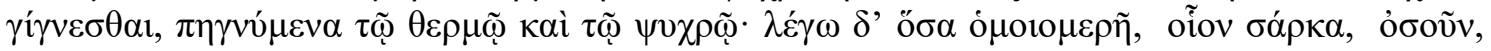

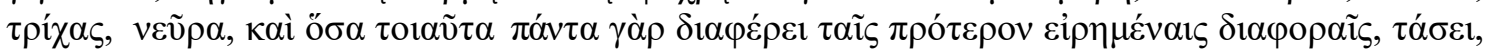


Na passagem referida mais acima dos Meteorológicos (390a14-20), após expor a noção de homonímia afirmando que, por exemplo, o olho somente é o que é na medida em que é capaz de ver, sendo aquele não apto a realizar essa função dito "olho" apenas homonimamente ${ }^{6}$, e sendo essa atividade aquilo que o caracteriza como tal e por meio da qual o definimos (Meteorológicos, IV.12, 390a12-14), Aristóteles declara o seguinte:

Assim, então, também a carne, mas a sua função é menos clara do que a da língua. Semelhantemente também o fogo, mas sua função natural é ainda menos clara que a da carne (390a14-16). De um modo semelhante, também, os componentes das plantas e os seres inanimados, como o bronze e a prata. Pois todos eles são por certa capacidade de atuar ou de ser atuado, como a carne e o tendão; mas as suas definições não são precisas (390a16-20). ${ }^{7}$

A tradução feita por H. D. P. Lee, na edição da Loeb Classical Library, referente ao trecho 390a17-20, é a seguinte:

It is equally true of plants and inorganic bodies like bronze and silver, for they are all what they are because of their ability to perform some active or passive function, like flesh and sinew. (373)

Lee introduz na passagem citada o termo "function", retomando ou fazendo referência à ideia de Épyov expressa no período imediatamente anterior, de modo a aproximar esse conceito à capacidade de atuar e de ser atuado dos compostos homogêneos. Entendo que tal introdução, além de ser desnecessária não seria correta.

Por um lado, em 390a14-16, Aristóteles faz menção à carne, um composto homogêneo animado enquanto componente de uma parte não homogênea no organismo


que compõe uma parte não homogênea, tendo essa parte a capacidade de realizar determinada função orgânica, ou vital (no homem, por exemplo, a língua desempenha duas funções: (i) proporcionar a percepção dos sabores, e (ii) permitir a articulação dos



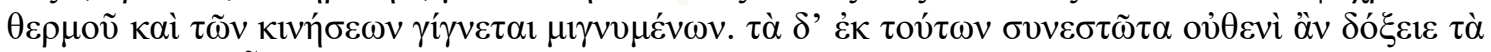



${ }^{6}$ Neste sentido, de acordo com Aristóteles, não se deve pensar nos organismos vivos em termos de configuração externa, como Demócrito equivocadamente supunha, ao pretender que o homem

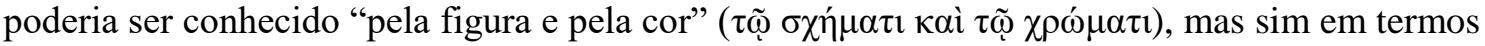
de função, ou conjunto articulado de funções, em vista do qual ele vem a ser como tal e pelo qual apreendemos a sua definição, o seu logos (Partes dos Animais, I.1, 640b29-641a5).

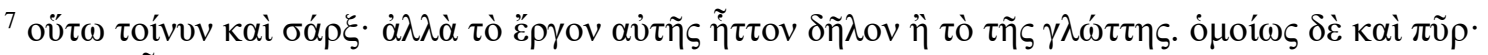

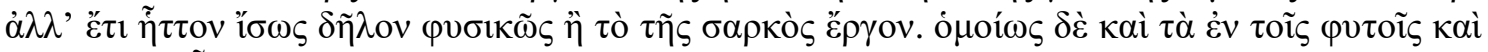

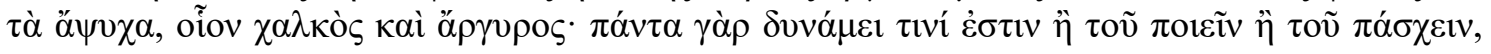

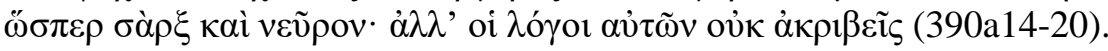


fonemas e a linguagem (Partes dos Animais, II.17, 660a17-23)). Mas, por outro lado, entendo que, em 390a16-20, Aristóteles faz menção à carne enquanto, simplesmente, um composto homogêneo, tal como também as composições homogêneas inanimadas, independentemente de compor ou não uma parte não homogênea no organismo vivo.

A ideia de ह̌pyov - termo que poderia, dependendo do contexto, ser associado ao sentido de "função", mas também, ao sentido de "atividade", de "operação própria", ou, simplesmente, de "operação" - ligada aos compostos homogêneos de um modo geral, diz respeito, estritamente, à consideração sobre a capacidade que as potencialidades ativas, ou seja, o calor e o frio têm de atuar sobre as potencialidades passivas, a saber, umidade e sequidade dos componentes materiais. As potencialidades ativas determinam a composição homogênea, isto é, o calor ou o frio incorporado a certa mistura ao "dominar a matéria" (Meteorológicos, IV.1, 379a1). Esta determinação ocorre na medida em que o grau de umidade e de sequidade que caracteriza o composto enquanto tal, estabelecido pelas atividades ativas, atribui certa consistência ao sólido, ao corpo homogêneo (Meteorológicos, IV.1, 378b10-379a11, 379a16-18; IV.4, 381b24-27; IV.8, 384b24-26).

Neste sentido, não seria correta a ideia de que os corpos homogêneos se caracterizariam pela capacidade de realizar certa função ativa ou passiva. Assim, em 390a14-16, a funcionalidade atribuída a uma parte homogênea animada, a saber, a carne, e ao elemento fogo que compõe essa parte, deve ser pensada, estritamente, em relação à língua, uma parte não homogênea composta na base pelo elemento fogo, e de uma maneira mais próxima pela carne. Deste modo, a função da carne não seria clara, e menos ainda a do fogo, relativamente à língua e de uma forma geral ao organismo como um todo.

Por outro lado, no trecho logo em seguida, em 390a16-20, a carne e o tendão devem ser considerados como exemplos de composições homogêneas simpliciter ${ }^{8}$ - e não em relação aos compostos não homogêneos, dos quais elas são partes no organismo -, tais como, também, os compostos homogêneos inanimados, sendo as suas definições ${ }^{9}$

\footnotetext{
${ }^{8}$ M. L. Gill, em seu artigo Material Necessity and Meteorology IV 12, no qual a autora oferece uma tradução do cap. 12 do livro IV dos Meteorológicos, menciona o fato do capítulo apresentar muitas ambiguidades (GILL, M. L., 1997, p.149).

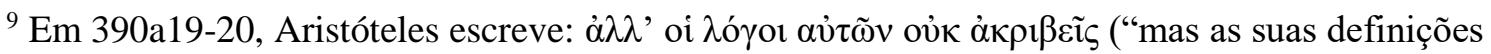

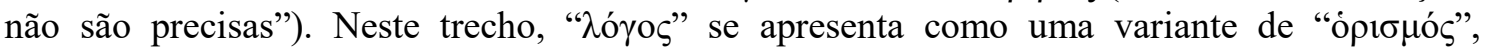
expressando, então, um sentido próximo ao de "definição". Este sentido de "logos" estaria



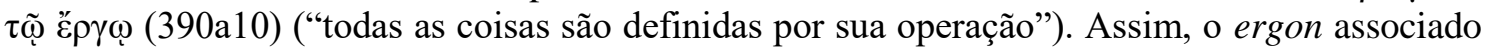
aos corpos homogêneos - considerados em si e por si mesmos -, por meio do qual eles são
} 
imprecisas não por que eles comportariam fatores funcionais não muito claros, como é clara, por exemplo, a função de ver referente ao olho (Meteorológicos, IV.12, 390a1112), mas porque as propriedades essenciais do bronze, por exemplo, não seriam precisas: certa fusibilidade, certa ductilidade, certa impressionabilidade etc.

Nenhuma das propriedades características que seriam exibidas, por exemplo, pelo bronze, dentre as quais uma delas é compartilhada também pela cera, a saber, ser impressionável (Meteorológicos, IV.9, 386a17), especificam de um modo bem definido um caráter próprio ou definitório: o bronze e o ferro são duros (Partes dos Animais, I.1, 642a10-11), porém o duro e o brando são indefiníveis quanto ao mais e ao menos, isto é, quanto ao grau relativo de dureza ou de brandura (Meteorológicos, IV.4, 382a16-17). Assim, a mistura dos elementos que compõe certo corpo homogêneo não apresenta uma mesma proporção relativamente a outro tipo de composição homogênea, de modo que a carne encerra em si uma proporção distinta de elementos materiais que constituem, por exemplo, o osso (De Anima, I.4, 408a14-15). A proporção dos elementos, que formam os diversos tipos de corpos homogêneos, se estabeleceria de acordo com graus variáveis de



Em contraste com a visão tradicional, segundo a qual Aristóteles sustentaria a ideia de uma teleologia universal na medida em que todos os corpos naturais viriam a ser gerados em função de um fim específico, ou em função de certo propósito natural, Mary L. Gill sustenta que, com base, também, nos Meteorológicos, IV.12, Aristóteles parece adotar uma concepção conforme a qual as composições homogêneas poderiam vir a serem geradas fora de um contexto teleológico por fatores estritamente materiais, e que tais composições de certo modo poderiam ser explicadas exclusivamente por uma necessidade de caráter material, em função, tão somente, da atuação do calor e do frio.

Meteorology IV 1-11 investigate [...] uniform compounds, analyzing their dispositional properties and their elemental constitution. There is no appeal to teleology. The behavior these materials is




atuam como princípio causal eficiente sobre as propriedades dos componentes materiais através


determinar a natureza própria de dada mistura homogênea. Esta natureza corresponderia a certo grau de umidade e de sequidade que delimita, enquanto potencialidade passiva, as propriedades essenciais de caráter qualitativa do composto como um todo (Meteorológicos, IV.1, 378b21-25; IV.5, 382a27-382b1; IV.8, 385a4-8). Desta forma, a referência do genitivo " $\alpha$ ṽ๊̃v", em 390a1920 , remeteria aos compostos como os componentes das plantas, o bronze, a prata, a carne, o tendão mencionados em 390a17-19, isto é, a um conjunto de seres na medida em que são considerados enquanto pertencentes à categoria dos corpos homogêneos de um modo geral. 
explained by ordinary material mechanics - processes like heating and cooling - which we shall call "material necessity" or "material causation". The situation is quite different in the biological sphere (GILL, M. L., 1997, p. 146).

Assim como Gill, estarei de acordo quanto à objeção direcionada à visão de que Aristóteles adotaria a ideia de uma teleologia universal. Porém, a concepção da autora segundo a qual os corpos homogêneos, tomados em si e por si mesmos, poderiam ou deveriam ser explicados por fatores estritamente materiais não parece ser plenamente satisfatória, em função, principalmente, de duas razões. A primeira razão diz respeito à consideração de que explicações em termos, unicamente, de causalidades materiais se restringiriam aos casos das composições elementares, as quais não comportariam quaisquer elementos de natureza formal.

As composições elementares, tais como a água de um lago ou a terra de uma montanha, seriam, diferentemente das composições homogêneas e dos organismos vivos, apenas agregados nos quais as suas partes composicionais se relacionam por meio de uma mera justaposição (e, por isso, não representariam uma unidade substancial propriamente dita). Nestes casos, não se faz presente, no processo gerativo, uma causalidade de tipo formal (Geração e Corrupção, II.7, II.3; Metafísica, VII.16, 1040b5-10; Cohen, S. M., 1996, p. 131). Sendo assim, com relação aos compostos elementares, não haveria alguma determinação de caráter formal envolvida em suas constituições, de modo que as composições se dariam em função tão somente de suas propriedades materiais.

As composições homogêneas, distintamente dos agregados elementares, se constituem por meio de um processo de cocção capaz de gerar determinada mistura, na qual o todo composicional passa a adquirir certas propriedades distintas - por exemplo, certa dureza, certa fragmentabilidade, certa fusibilidade etc. - daquelas dos elementos, isto é, o fogo, o ar, a água e a terra, que o constitui: quente, frio, úmido e seco. ${ }^{10}$ Apesar de não apresentarem um conjunto complexo e articulado de partes constituintes, os compostos homogêneos representam determinadas misturas, nas quais os componentes envolvidos sofrem alterações (Geração e Corrupção, I.10, 328b21-22), de modo a gerar

${ }^{10} \mathrm{O}$ fogo se caracteriza por ser quente e seco; o ar, por ser quente e úmido; a água, por ser fria e úmida; e a terra, por ser fria e seca (Geração e Corrupção, II. 3, 330b3-5). De acordo com Gotthelf, estas propriedades essenciais dos elementos corresponderiam ao que ele denomina de (i) natureza (nature), e de (ii) potencialidades (potentials), sendo posteriormente designados sob uma única expressão: "elementos-potenciais". A natureza de um corpo simples "é locomotiva, e suas potencialidades - seus modos característicos de interagir com tais outros corpos - são principalmente qualitativas: cada um possui um par de qualidades primárias, e isto é o que determina as suas interações" (Gotthelf, A., 1987, pp. 211-2). 
um todo distinto das partes que o constitui. ${ }^{11}$ Estas alterações acontecem no momento em

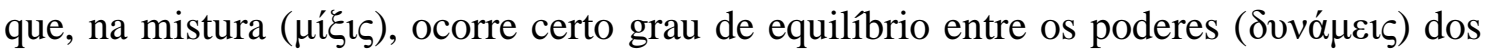
componentes, fazendo com que as diversas propriedades destes componentes se convertam em algo comum (Geração e Corrupção, I.10, 328a28-31).

A segunda razão pela qual não seria plenamente satisfatória a alegação de que a constituição dos corpos homogêneos seriam suficientemente explicados levando-se em conta, tão somente, fatores de natureza material, refere-se a uma passagem do capítulo 5 do livro IV dos Meteorológicos, na qual Aristóteles parece, claramente, conferir ao processo composicional dos corpos homogêneos de um modo geral (seja animados, como a carne ou osso, ou inanimados, como a prata ou o bronze) a atuação de uma causalidade de tipo formal, além da material:

Além da matéria há duas causas, a eficiente e a passiva: a eficiente [ $s c$. é aquela] da qual [sc. surge] o movimento, e a passiva, por exemplo, a forma. Assim também [sc. será no caso] da solidificação e da difusão, e do secar-se e do umedecer-se. A eficiente atua mediante duas potencias e o passivo padece [sc. em virtude] de duas afecções, como já se tem dito (Meteorológicos, IV.5, 382a27-32). ${ }^{12}$

Neste trecho, Aristóteles faz menção a duas causas ligadas à natureza formal, além da material: a causa eficiente e uma causa passiva que ele associa à forma. No presente contexto, a causa eficiente estaria relacionada, precisamente, à ação do calor e do frio como fatores co-responsáveis por - consoante suas operações próprias ou características - espessar e solidificar determinada mistura de elementos, de modo a gerar certo composto homogêneo (Meteorológicos, IV.8, 384b24-26). O calor e o frio, atuando como potencialidades ativas, passariam, então, a interagir sobre as potencialidades passivas, de natureza material, isto é, sobre certo grau de proporção de umidade e de sequidade do

\footnotetext{
${ }^{11}$ Theodore Scaltsas, no seu artigo Mixing the Elementes, afirma que, embora seja criada uma nova entidade com a geração do misto por meio de seus componentes elementares, não se trataria de uma composição substancial (SCALTSAS, T., 2013, p. 4). Ao contrário do que ele afirma, penso que, a partir da geração de uma composição homogênea inanimada ou de um misto, temse, de fato, uma composição substancial. Os compostos naturais que não comportariam o caráter de ser, de fato, substâncias se restringiriam aos agregados elementares. O misto teria o caráter de substância, justamente na medida em que as propriedades essenciais que o caracterizam como tais passam a ser distintas daquelas propriedades próprias de seus componentes materiais, mesmo que de uma maneira rudimentar relativamente aos organismos vivos.

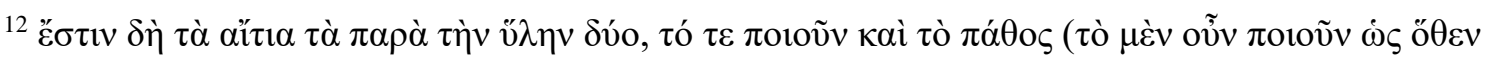



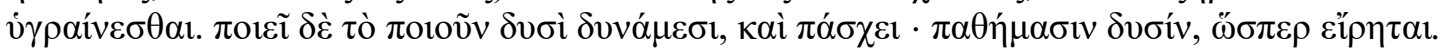


composto, de modo a estabelecer, de uma maneira passiva, a forma de determinado corpo homogêneo. ${ }^{13}$

Desta maneira, a forma do composto homogêneo ou do misto seria considerada como uma causa passiva, na medida em que a forma ou a natureza essencial desse composto corresponderia, justamente, ao acabamento pelo qual se dá a solidificação característica que resulta da atuação da causalidade eficiente. No entanto, será que poderíamos, ainda assim, sugerir a ideia de que não haveria, de modo algum, apesar da atuação da causalidade de tipo formal, um aspecto de ordem teleológica envolvido no processo em questão?

Na passagem supracitada (382a27-32), Aristóteles não faz menção à causa final. Contudo, faria sentido supor que a causa formal e a causa final, no caso dos mistos, corresponder-se-iam entre si, com base em um trecho do Livro II da Física, o qual declara que muitas vezes, ou em certos contextos específicos, o "o que é" (a causa formal) e "aquilo em vista de quê" (a causa final) convergem para uma coisa só - além, inclusive,

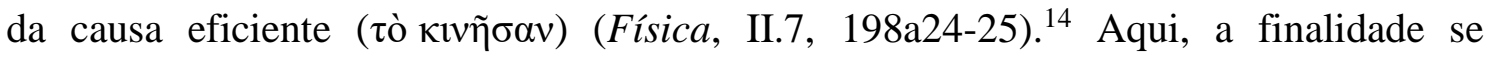
restringiria ao acabamento pelo qual a forma do corpo homogêneo inanimado vem a ser constituído e caracterizado (aspecto ao mesmo tempo formal e final), pelas suas

\footnotetext{
${ }^{13}$ No livro XII da Metafísica, Aristóteles faz menção também ao caráter formal ligado, de certa forma, ao calor e ao frio, tidos como princípios ativos no processo gerativo das composições homogêneas: "Seguramente o calor é a modo de forma [eidos] dos corpos sensíveis e o frio é, a sua maneira, a privação, enquanto a matéria será aquilo que, primeiramente e por si, é em potência um e outro, e substâncias serão essas coisas, assim como as que procedem dessas tendo eles como princípios, ou se algo dotado de unidade gera-se a partir do calor e do frio, por exemplo, carne ou osso" (Metafísica, XII.4, 1070b11-15). Pode-se notar, neste trecho, que Aristóteles concebe a ideia de que, a partir da atuação do calor em dada mistura de elementos, tal qual a carne ou o osso, gera-se uma unidade, ou em termos aristotélicos, "um isto" ( $\tau o ́ \delta \varepsilon \tau \imath$ ), sendo, portanto, algo separado ( $\chi \omega \rho ı \tau \tau o ́ v)$ das demais coisas. Ora, ser "um isto" e ser "separado" são, justamente, os fatores que Aristóteles, na Metafísica, atribui como critérios para qualificar algo como sendo uma ov̉oía, ou seja, uma substância (Metafísica, V.8, 1017b25). O todo composicional, na mistura de elementos que constituem um composto homogêneo, adquire outras propriedades essenciais, ou formais, por exemplo, certa maciez, certa ductibilidade, certa fusibilidade etc., em relação às propriedades características próprias do elemento, ou dos elementos, que compõe(m) este todo, por exemplo, o quente e o seco do elemento fogo, o frio e o seco do elemento terra etc.

${ }^{14}$ Não pretendo, aqui, desenvolver um exame detalhado da teoria aristotélica das quatro causas. Sendo assim, não tratarei a respeito dos modos pelos quais a causa formal, a causa final e a causa eficiente se convergiriam, nos casos em que esta questão poderia ser tratada como uma investigação em torno dos diversos tipos de substâncias, sejam elas naturais ou artificiais. Do mesmo modo, não tenho a intenção, neste âmbito de discussão, de examinar em quais sentidos esta convergência entre as referidas causas poderiam, ou não, ser concebidas. O ponto a ser salientado refere-se exclusivamente a uma análise comparativa entre as características formais e finais dos organismos vivos e dos corpos homogêneos.
} 
propriedades passivas e essenciais, tais como, ser fundível de certo modo, ser quebradiço de determinada maneira, ser maleável sob certas condições etc.

De outro modo, quanto às composições homogêneas orgânico-animadas, apesar da ideia referida acima de que algumas vezes a causa formal e a causa final podem convergir-se entre si, haveria, distintamente das composições homogêneas inanimadas, uma diferença notória de aspecto relativamente ao fator formal e ao fator final. Embora o acabamento de um organismo vivo coincida com as atividades funcionais pelas quais ele exerce suas atividades anímicas ${ }^{15}$, poder-se-ia destacar nesse acabamento de uma maneira analítica, em primeiro lugar, o todo orgânico sem o qual não se daria as funcionalidades orgânicas (causa propriamente formal), e, em segundo lugar, as funcionalidades orgânicas tomadas em si próprias (causa propriamente final).

Em seu artigo intitulado Differents Conceptions of the Final Cause in Aristotle, W. Kullmann estabeleceu uma distinção entre, por um lado, um acabamento

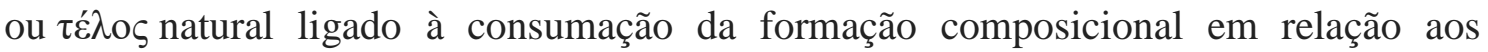
primeiros estágios e, por outro, um $\tau \varepsilon ́ \lambda o \varsigma$ natural ligado à realização das funções ou atividades vitais (170). Neste sentido, talvez seria plausível atribuir aos corpos homogêneos apenas o sentido de teleologia ligado ao ponto (i), como discernido por Kullmann. Sendo assim, tanto (i) os corpos homogêneos quanto (ii) os organismos vivos seriam caracterizados por certo atributo teleológico, porém, tal atributo, em relação a um e outro tipo de substância natural, seria completamente distinto: com relação aos primeiros (i), a finalidade estaria associada apenas às qualidades que resultam do acabamento composicional e que determinariam a especificidade de dado composto homogêneo. Já no caso dos segundos (ii), além do acabamento composicional, seria preciso, principalmente, levar em conta tal acabamento para possibilitar ao organismo vivo a capacidade de realizar um conjunto articulado de funções anímicas, que o caracteriza como tal, ou seja, como um vivente.

Com efeito, como notado por James G. Lennox (2014, p. 276, nota 5), há, em certas passagens nas quais Aristóteles examina a atividade de cocção ( $\pi \dot{\varepsilon} \psi 1 \varsigma)$ no processo

\footnotetext{
${ }^{15}$ Neste sentido, na Geração dos Animais, Aristóteles declara o seguinte: "admite-se que há quatro causas, a do 'para quê' como fim, a definição da essência (de fato, essas duas há que considerá-las quase como uma só); a terceira e a quarta são a matéria e 'aquilo de onde provém o movimento"' (Geração dos Animais, I.1, 715a4-7).
} 
gerativo dos corpos homogêneos em Meteorológicos IV, algumas ocorrências do termo

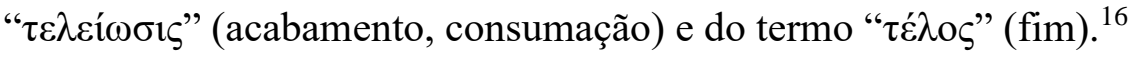

A cocção é o acabamento pelo calor natural e próprio a partir de [ $s c$. fatores] passivos e opostos: estes são a matéria própria de cada coisa. Com efeito, quando chega à cocção, é consumada e gerada. E o princípio do acabamento se dá pelo calor próprio, ainda que seja levado a termo, também, pela ajuda de algo externo (Meteorológicos, IV.2, 379b18-23). ${ }^{17}$

O fim, para algumas coisas, é a natureza, a saber, a que chamamos forma e essência; para outras, o fim da cocção é uma forma subjacente, quando o úmido adquire tal qualidade e tal quantidade ao ser assado, fervido, passado ou esquentado de qualquer outra maneira (Meteorológicos, IV.2, $379 \mathrm{~b} 25-29) .^{18}$

No entanto, Lennox parece descartar, ou não reconhecer, a possibilidade de atribuir aos corpos homogêneos algum aspecto de teleologia, ou de considerar algum tipo de causalidade final na análise das determinações constituintes desses corpos, em função

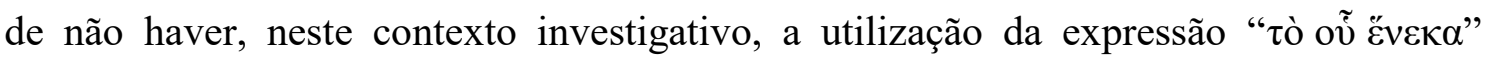

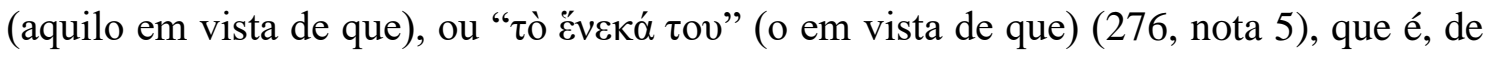
modo amplo, empregada no exame de caráter notoriamente teleológico - no sentido de funções vitais - dos organismos vivos.

Contudo, pelo fato de Aristóteles lançar mão dos termos " $\tau \varepsilon \lambda \varepsilon i ́ \omega \sigma ı \varsigma "$

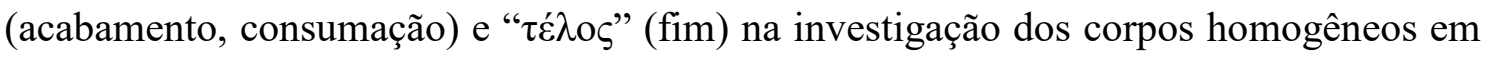
Meteorológicos IV, talvez seja precisamente o caso de se levar em conta certo sentido de teleologia ligado a esses $\operatorname{corpos}^{19}$, como aquele discernido por Kullmann, isto é, uma finalidade associada, puramente, à consumação "de um processo de desenvolvimento em relação aos seus estágios preliminares (170). Isto fundamentalmente pela razão de que, distintamente dos agregados, os corpos homogêneos apresentam certo atributo formal em

16 Outras passagens manifestam, ainda, a ocorrência do termo "atéleia" (não acabamento, imperfeição). Nestes casos, são considerados os processos gerativos dos corpos homogêneos que não chegam a realizar um estado de composição plena, na medida em que não ocorre uma cocção (apepsia) devido à falta de calor próprio necessário para delimitar a proporção de umidade, que determinará a especificidade de dada mistura de componentes elementares.



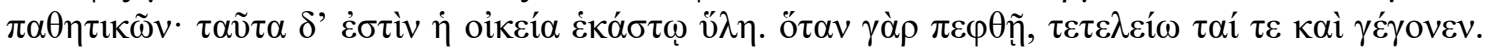

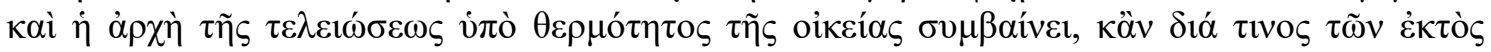

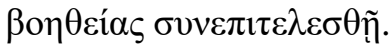







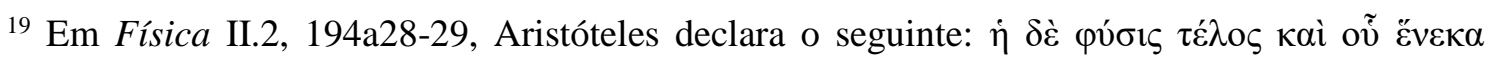
("natureza é acabamento e aquilo em vista de quê"). 
sua natureza constitutiva, na medida em que a atividade de cocção, a qual atuaria como causalidade formal, internaliza o calor externo do ambiente na matéria composicional em

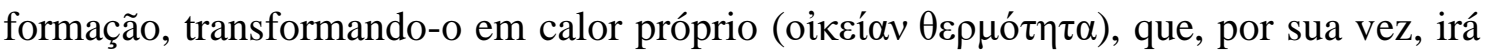
determinar o acabamento em relação ao qual se estabelece, de uma maneira passiva, a emergência de outras propriedades qualitativas relativamente àquelas dos componentes elementares.

Não obstante, poder-se-ia, tal como faz Christopher V. Mirus, argumentar e procurar sustentar a ideia de que, talvez, os compostos homogêneos considerados em si e por si próprios, de fato, possuiriam um aspecto teleológico funcional, mas não do mesmo modo que os organismos vivos. Seria então possível que, neste sentido, certo tipo de funcionalidade inerente aos corpos homogêneos distinta das funções vitais dos organismos vivos. ${ }^{20}$

But if there is also a homogeneous stuff called flesh, which is not essentially living, why should it not have a function or functions of it own? (Mirus 2006, p. 49)

The function of iron is, presumably, a matter of its being relatively shapeable when heated, but strong and resistant to change when cooled. (p. 61)

Contudo, a meu ver, haveria dois problemas fundamentais implicados nesta consideração. O primeiro residiria no fato de que não seria possível tomar, de uma forma estrita, os corpos homogêneos animados como, essencialmente, substâncias propriamente ditas, pois eles não possuem uma existência autônoma, de modo que eles se apresentariam, portanto, em si e por si mesmos como pseudo-substâncias (Lewis 1994, p. 266).

Estes corpos animados (a carne ou o osso etc.), se considerados essencialmente como tais, e não tomados em si e por si próprios, de uma maneira abstrata, ou de um modo concreto, porém, não mais animados (e, por conseguinte, não mais enquanto tais), sempre comportam uma existência relativa, isto é, o seu ser existe em relação às capacidades orgânico-funcionais do ser vivo como um todo. Isto significa que estes corpos homogêneos sempre vão ter uma característica de funcionalidade orgânico-ativa ou,

${ }^{20}$ Parece que esta ideia seria sustentada, também, além de Mirus, por S. M. Cohen: "He [sc. Aristotle] says that although flesh and bone, and even fire and water, have a final cause, and though what they are is determined by their functions (even if their definitions are not apparent [390a19], somehow the functions of flesh, bone, bronze, and silver are accounted for by the sort of characteristics listed, and these characteristics can in turn be accounted for by the action of heat and could, But no one, he adds, would suppose this to be the case for the head or the hand, or for a saw or a box" (Cohen, S. M., 1996, p. 139). 
orgânico-dinâmica, mesmo que este caráter de ordem teleológica não seja muito evidente, relativamente às partes não homogêneas das quais eles fazem parte, e, de um modo geral, ao organismo como um todo.

Por outro lado, o segundo problema estaria relacionado à natureza própria dos compostos homogêneos de um modo geral, sejam eles inanimados, ou em certo sentido animados. $^{21} \mathrm{Se}$ considerássemos como fator essencial uma característica passivofuncional do todo composicional destes compostos, esse fator não seria intrínseco aos corpos em questão, sendo que, portanto, não poderia ser considerado como um elemento essencial ou definitório a eles relacionado. Por exemplo, se, para o caso do ferro, dependesse (i) do calor ou (ii) do frio ambiente para um fator passivo-funcional se apresentar como característica essencial desse composto, na medida em que o ferro, respectivamente, exibisse (i) certa capacidade de ser moldado, ou (ii) certa capacidade de ser resistente, então, tais características não seriam um fator inerente a ele, e, por conseguinte, não seria um fator substancialmente essencial ou formal.

Em outros termos, se determinado corpo homogêneo fosse caracterizado por certos fatores passivo-funcionais, as suas propriedades essenciais não seriam atributos independentemente associados à natureza própria do composto em questão, mas sim determinadas em relação a algo. Atribuir a dado corpo homogêneo um caráter essencial por ter, por exemplo, a capacidade ou a função passiva de ser fundível, ou ter a funcionalidade passiva de comportar certa fundibilidade, dependeria de algo além dele próprio para ser fundamentalmente distinguido como tal. Neste sentido, para que certo corpo homogêneo possa ser determinado pela capacidade de ser fundível é necessária uma ação de fundibilidade, e esta ação decorre de algo externo ao corpo em particular em questão. $\mathrm{O}$ ferro, por exemplo, não se funde por si mesmo, mas depende de certo fator externo para ser fundível, sob determinado modo específico.

No entanto, ao invés de considerar que o corpo homogêneo seria distinguido essencialmente por certas funcionalidades de natureza passiva, penso que, como visto anteriormente, esses corpos seriam caracterizados como tais tão somente por suas

\footnotetext{
${ }^{21}$ Compostos homogêneos animados considerados estritamente, neste caso, como abstraídos do contexto orgânico-vital, ou de um modo concreto, na medida em que preservam de certa forma o caráter de substância homogênea após a morte do organismo vivo, como, por exemplo, o osso. Mas o osso, mesmo que ainda preserve, por algum tempo, certas propriedades essenciais de um corpo homogêneo após a morte do animal, ele não seria mais, propriamente, um composto homogêneo animado, pois deixa de atuar como parte de um organismo vivo, em relação ao qual veio a ser de uma maneira essencial gerado como tal.
} 
qualidades próprias, as quais se mantêm intimamente, ou substancialmente, vinculadas ao seu acabamento composicional, como, por exemplo, certa fundibilidade, certa fragmentabilidade, certa maleabilidade etc. Estas qualidades, sob a condição de propriedades essenciais dos compostos homogêneos, se manifestariam na exata medida em que o calor do meio vem a ser internalizado à mistura de elementos que irá compor o misto, de modo a gerar um processo de cocção (Meteorológicos, IV.11, 389b7-9; Partes dos Animais, II.2, 649a24-25), a partir do qual, após um período de esfriamento, formará o corpo homogêneo de acordo com certo grau de equilíbrio entre o úmido e o seco (Meteorológicos, IV.4, 381b25 e ss.).

Voltando, agora, à problemática do trecho em análise dos Meteorológicos, 390a16-20² , logo em seguida, em 390a20, Aristóteles faz menção à dificuldade de identificar quando os fatores formais e definitórios estão ou não presentes nos compostos homogêneos de um modo geral.

Não é fácil discernir quando se encontra ou quando não [sc. as propriedades essenciais ou definitórias dos copos homogêneos], a não ser que [sc. o corpo] esteja muito degradado e só permaneçam as formas externas como, por exemplo, os corpos [sc. de homens] mortos há muito tempo atrás, que se convertem repentinamente em cinzas dentro das tumbas (Meteorológicos, IV.12, 390a20-23). ${ }^{23}$

Penso que é no tocante às afecções próprias dos compostos homogêneos, tais como ductilidade, maleabilidade etc., diretamente implicadas pela "certa capacidade de


o filósofo se refere sobre a dificuldade acima citada. Desta forma, somente quando certas partes homogêneas do organismo, as quais, à maneira de agregados, comporiam

22 "Assim, então, também a carne, mas a sua função é menos clara do que a da língua. Semelhantemente também o fogo, mas sua função natural é ainda menos clara que a da carne. De um modo semelhante, também, os componentes das plantas e os seres inanimados, como o bronze e a prata. Pois todos eles são por certa capacidade de atuar ou de ser atuado, como a carne e o tendão; mas as suas definições não são precisas".



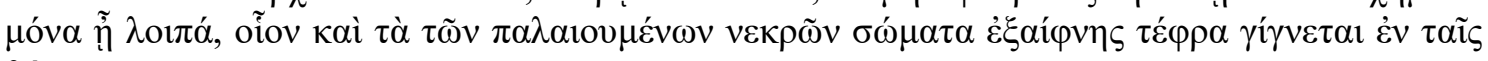
$\theta \dot{\eta} \kappa a 1 \zeta$.

${ }^{24}$ Corpos estes entendidos na medida em que os inanimados, como o bronze e a prata, são considerados $\kappa \alpha \theta$ ' avi $\alpha$ ("por si mesmos"), e os animados, como a carne e o osso, considerados


qual eles, essencialmente, fazem parte, e (ii) $\kappa \alpha \theta$ ' avi ó ("por si mesmos") na ocasião da morte do ser vivo. Ou, ainda, quando um membro ou uma parte do organismo vivo é desvinculado do todo orgânico, em virtude, por exemplo, da amputação de um braço, que é composto por carne, osso etc.; com a ressalva de que, nestes casos referentes ao ponto (ii), a carne ou o osso não seriam mais definidos, estritamente, como "carne" ou "osso". 
cadáveres muito antigos ${ }^{25}$, preservando alguma "forma orgânica" das partes não homogêneas apenas com relação à configuração externa, e estando bastante degradados ao ponto de se converterem em cinzas nos sepulcros (Meteorológicos, IV.12, 390a20-23), que seria possível, então, determinar com maior precisão a ausência de suas características essenciais.

Examinemos o caso do sangue. Na medida em que o sangue no organismo vivo é considerado, in abstracto, como uma substância em particular, ele exibe as propriedades de ser frio e de ser sólido. Mas na medida em que é considerado essencialmente como tal, ele exibe as propriedades de ser quente e líquido (Partes dos Animais, II.3, 649b27-30). É interessante notar que, neste caso, como bem observou Lewis (273), as propriedades essenciais ou formais do sangue, tomado em si e por si mesmo, advém-lhes de uma maneira externa e não intrínseca. O sangue precisa passar por um processo de cocção, proveniente do calor vital orgânico-corporal para adquirir a sua propriedade essencial ou formal.

The salient feature of blood is that its heat is externally derived. Its heat comes not from its matter, namely (predominantly) earth and water, both of which are cold, but from its efficient cause. Blood must be concocted out of the animal's food by the animal's nutritive soul, which 'makes' growth out of the nourishment using heat and cold as its instruments (Lewis 1994, pp. 262-263).

A propriedade essencial de ser quente do sangue é derivada através de uma causa eficiente, a saber, do calor vital procedente do coração, que é capaz de cozer o alimento de modo a transformá-lo em sangue (Lewis 264). Desta maneira, pode-se perceber uma diferença fundamental entre (i) os corpos homogêneos inanimados e (ii) os corpos homogêneos animados: o primeiro (i) não é caracterizado por uma propriedade externa a ele, visto que tais corpos existem na natureza de uma forma autônoma; por sua vez, (ii) os compostos homogêneos animados não existem de uma forma autônoma na natureza, sendo que eles dependem de propriedades formais externas enquanto considerados em si e por si próprios, mas, no tocante a sua natureza essencial, ou seja, enquanto parte de um organismo vivo do qual depende para existir, estas propriedades formais devem ser

\footnotetext{
${ }^{25}$ Com efeito, Aristóteles diz que um homem morto estaria mais bem constituído de "carne" ou de "osso" do que de mão ou de braço (Geração e Corrupção, I.5, 321b31-32), visto que o organismo vivo, na ocasião da morte, deixa de apresentar as suas propriedades formais, as quais estão associadas aos fatores orgânico-funcionais das partes não homogêneas e da compleição orgânica como um todo.
} 
consideradas como internas. Tais propriedades seriam, então, examinadas em relação à compleição orgânica, e não relativamente a sua realidade particular.

Assim, o sangue deixaria de apresentar as suas características formais, na ocasião em que vem a ser desprovido da condição comportamental dinâmico-orgânica, isto é, da condição comportamental de natureza fundamentalmente vital. Na medida em que o sangue, essencialmente associado ao organismo vivo, deixa de manifestar o seu caráter anímico, ou seja, deixa de manifestar o conjunto geral e articulado de funções vitais, como integrante responsável por possibilitar ao vivente o ato reprodutivo ou o ato perceptivo etc., em função da morte ele deixa, ao mesmo tempo, de manifestar as suas propriedades essenciais ou formais, as quais o caracterizam como tal.

Quanto ao corpo homogêneo inanimado, ele deixa de apresentar as suas propriedades formais e, portanto, deixa de ser enquanto tal, na medida em que o calor próprio, incorporado ao composto na ocasião de sua geração mediante o processo natural de cocção (Meteorológicos, IV.11, 389b7-8; IV.2, 379b18-21), não é mais capaz de preservar ou de delimitar a proporção de umidade característica (Meteorológicos, IV.1, 379a23-25; IV.2, 379b33-35). Como notou Freudenthal, o corpo homogêneo mantém certa coesão entre os elementos da mistura substancial (1995, p. 41) ${ }^{26}$, na medida em que não vem a ser dominado e, por isso, destruído pelo calor ou pelo frio (Meteorológicos, IV.1, 379b3-4) externo do ambiente (cf. Meteorológicos, IV1, 379a16-18), sendo que não seria fácil determinar quando isto ocorreria ou não.

Por outro lado, não seria difícil determinar quando se dá ou não as propriedades essenciais da constituição orgânica, já que seria mais claro constatar que um cadáver se diz homem apenas homonimamente (Meteorológicos, IV.12, 389b31). Isto porque a natureza formal, ou a alma, dos seres vivos de um modo geral corresponde a um conjunto articulado de faculdades funcionais, tais como a nutritiva ( $\theta \rho \varepsilon \pi \tau 1 \kappa o ́ v)$, a sensitiva


II.3, 414a31-32). Com a morte do organismo vivo, a constituição orgânica como um todo deixa de manifestar estas faculdades responsáveis por capacitá-la ao exercício das atividades vitais, como nutrir-se, reproduzir-se etc.

\footnotetext{
${ }^{26}$ Aristóteles alega que o elemento terra está presente em todos os corpos, porém, a terra, ao compor uma mistura, não poderia permanecer firme sem a umidade, visto que é por meio dessa que aquela se mantém compacta, de modo que, sem a umidade, o elemento terra não se manteria coeso ao composto (Geração e Corrupção, II.8, 334b31-335a3).
} 
Com efeito, as propriedades essenciais e os aspectos definitórios de uma substância natural estão sempre mais claros no caso dos seres que são como "instrumentos

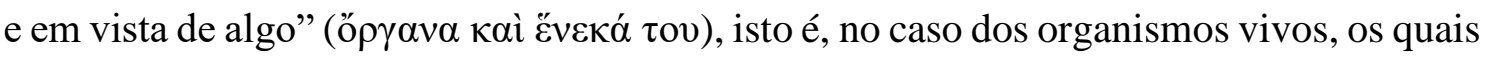
são diretamente constituídos por um conjunto intrinsecamente articulado de partes orgânicas, ou instrumentais (Partes dos Animais, II.1, 646b26); como por exemplo, os olhos, o coração, as mãos, os pés etc., em vista da realização das atividades ou das funções vitais (Meteorológicos, IV.12, 389b28-30).

Isto [sc. a forma] é ainda mais manifesta nos corpos não homogêneos, como a mão [...]. Ali, de fato, a matéria resulta mais manifestamente diversa da forma, relativamente ao caso da carne e das coisas homogêneas; e por isso poder-se-ia supor que um homem morto está bem mais constituído de carne e de osso, do que de mão e de braço (Geração e Corrupção, I.5, 321b28$32) .{ }^{27}$

As substâncias homogêneas, como os objetos extraídos das minas, os $\mu \varepsilon \tau \alpha \lambda \lambda \varepsilon v o ́ \mu \varepsilon v \alpha$, isto é, o cobre, o ouro, a prata, o ferro etc. (Meteorológicos, IV.10, 388a13-16), diferentemente dos agregados elementares que, apesar de apresentarem certa "unidade", preservam no composto as propriedades materiais como tais ${ }^{28}$, não deixariam de apresentar certo acabamento ( $\tau$ ò $\tau \varepsilon ́ \lambda o \zeta)$ e uma natureza formal. Isto porque o corpo homogêneo adquire certas propriedades características comuns à composição como um todo, através do calor, do frio e dos movimentos por eles produzidos (Meteorológicos, IV.12, 390b2-4; Geração dos Animais II.1, 734b31-33, 734b37-735a1). Através de um processo de cocção, sob efeito do calor, certa combinação de elementos sofre determinada transformação. Os princípios correspondentes ao calor e ao frio fazem com que se atinja certo termo médio que irá demarcar o grau intermediário de umidade e de sequidade, o qual caracterizará, por sua vez, o logos ou a natureza da composição homogênea em formação (Geração e Corrupção, II.7, 334b24-30), consoante as qualidades próprias que a determinam enquanto considerada, sic et simpliciter, composição homogênea, como, por exemplo, certa maciez, certa dureza, certa viscosidade etc.

A partir de determinada combinação de elementos surgiria, então, certas propriedades emergentes associadas a um todo composicional de caráter misto, cujo

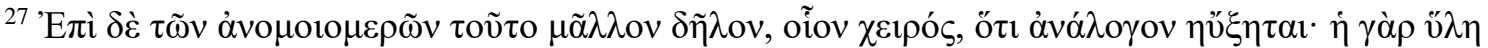

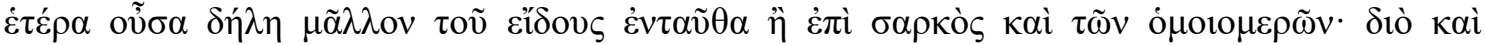

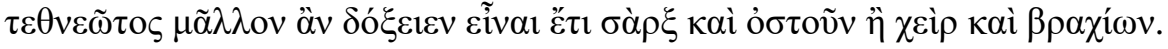

${ }^{28}$ Estas propriedades correspondem às quatro qualidades primárias, a saber, quente, seco, frio e úmido, sendo o fogo quente e seco, o ar quente e úmido, a água fria e úmida e a terra fria e seca (Geração e Corrupção, II.3, 330b3-5).
} 
acabamento por si só irá delimitar o $\tau \varepsilon ́ \lambda o \varsigma$ a este tipo de composição relacionado. Desta maneira, por um lado, os organismos vivos comportariam um $\tau \hat{\varepsilon} \lambda$ os de natureza ativa, que corresponde ao conjunto articulado de funções vitais e, por outro lado, os corpos homogêneos apresentariam um $\tau \varepsilon ́ \lambda o \varsigma$ de natureza passiva, caracterizado simplesmente por terem, por exemplo, certo grau de dureza, certo grau de fundibilidade, certo grau de solidificabilidade etc. Neste sentido, poder-se-ia, talvez, inferir ou depreender da filosofia natural de Aristóteles dois tipos distintos de teleologia natural: (i) uma teleologia passiva ligada ao acabamento dos corpos homogêneos, e (ii) uma teleologia ativa de natureza funcional ligada aos organismos vivos.

Ainda que o processo composicional dos corpos homogêneos venha a ser realizado espontaneamente a partir de uma necessidade "sem mais" ( $\dot{\alpha} v \alpha ́ \gamma \kappa \eta \dot{\alpha} \pi \lambda \tilde{\omega} \varsigma$ ), em função do calor ou do frio ambiente, e não a partir de um princípio anterior regulativo de

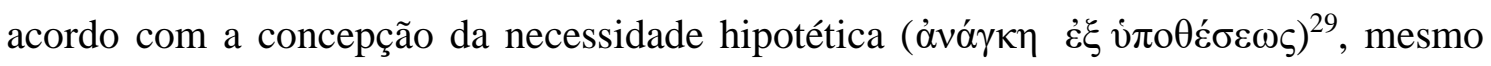

\footnotetext{
${ }^{29}$ A necessidade hipotética, ou a necessidade a partir de um princípio anterior, estaria restrita, em um sentido, à geração dos organismos vivos e, em outro, à produção dos artefatos. Embora haja relações de implicação lógica e explanatória na análise dos processos constitucionais técnicos e naturais, Aristóteles, no entanto, assinala uma diferença fundamental entre ambos: "naquilo que é conforme a técnica, somos nós que fazemos a matéria ser em vista da função, mas nos entes naturais a matéria já se encontra disponível [sc. em vista da função]" (Física, II.2, 194b7-8). Na técnica, somos nós o princípio que preside a constituição dos artefatos, fazendo com que a matéria torne-se adequada às funções que definem o produto do qual ela é componente. Quaisquer que sejam os propósitos técnicos, somos nós que alteramos as propriedades materiais, em vista de adequá-las ao desempenho de determinadas funções próprias aos artefatos. A técnica intervém sobre uma matéria que se encontra disponível na natureza de modo a introduzir propriedades que ela seria incapaz de adquirir por si própria. Por outro lado, na natureza, a matéria por si mesma, sem a necessidade da intervenção externa da técnica, adquire as propriedades adequadas ao exercício de certas funções. No tocante à técnica, tomando a parede como exemplo (Física, II.9, 199b35-200a5), as propriedades ou características essenciais próprias dos componentes materiais devem ser incorporadas por um princípio anterior, estipulado como hipótese, para que as devidas disposições composicionais, que constituem a parede, sejam efetivamente estabelecidas. Tal princípio, que corresponde originariamente a ideia de parede presente na mente do artífice, se estabelece, desde o início do processo composicional, como uma causalidade reguladora e externa relativamente aos componentes materiais que constituem a parede, isto é, terra, pedras e madeiras. Esta causalidade vem a ser executada pelo artífice, de modo a dispor terra, pedras e madeiras sob determinado arranjo estrutural, a fim de que a parede tenha a capacidade de cumprir as funções por meio das quais ela se realiza e é definida com tal, a saber, as funções de esconder, proteger, conservar determinados objetos etc. De outra parte, quanto aos seres naturais e tomando o caso do ser humano como exemplo, a potencialidade do princípio material de gerar um novo organismo especificamente idêntico é efetivada por meio de um princípio anterior, assumido como hipótese,

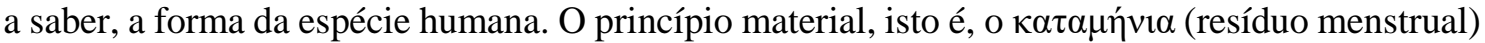
proveniente da mulher, no ato conceptivo, vem a ser fecundado pelo princípio formal procedente do homem (Geração dos Animais, I.2, 716a5-8), isto é, o esperma, o qual atua desde o início do processo como uma causalidade reguladora internalizada à natureza material, desencadeando, com isso, o processo de desenvolvimento das partes orgânicas. Tais partes determinarão o conjunto articulado de funções vitais que caracterizam o ser humano como tal.
} 
assim, tais corpos, durante o processo gerativo, passariam a comportar um elemento causal de natureza formal envolvido em seus desenvolvimentos constitutivos. Tal elemento causal corresponderia à atividade de cocção por meio do qual se internaliza o calor à composição mista, determinando certo grau intermediário das potencialidades passivas - variável em função de distintas combinações dos componentes elementares -, que caracterizará a forma de cada tipo de mistura segundo as suas qualidades próprias.

No intuito de procurar esclarecer melhor a questão do envolvimento de uma causalidade de tipo formal no processo gerativo dos corpos homogêneos, a partir de um entrecruzamento concomitante de interações materiais estritamente necessárias, talvez seja elucidativo traçar uma breve análise de comparação com a atividade formativa dos organismos gerados espontaneamente.

Os organismos vivos gerados por espontaneidade, pelo fato de não possuírem a capacidade reprodutora da alma, estando, por isso, sempre dependentes de condições externas favoráveis para serem continuamente produzidos, poderiam ter sido constituídos - mas, de fato, não foram - em vista do exercício pleno das capacidades anímicas. O exercício ou a atividade plena das capacidades anímicas não poderia ser realmente efetivado pela justa razão de ter-lhes faltado um princípio causal de tipo formal presidindo a devida concatenação das séries causais de caráter material-composicionais, como aconteceria no caso dos organismos vivos gerados por natureza, e não por espontaneidade. $^{30}$

De acordo com Augustin Mansion, o processo de geração espontânea não seria contrário "à ordenação teleológica que preside a produção de um ser natural" (Mansion, 1945, p. 308). No entanto, penso que ainda assim tal processo não deixaria de ser distinto do natural, visto que, como o próprio Mansion afirma: “o que se produz por geração

\footnotetext{
${ }^{30}$ Nós, modernos, estamos habitualmente acostumados a pensar como sendo natural tudo aquilo que seria regido por processos necessários. Mas na perspectiva da filosofia natural aristotélica, não basta que algo ocorra por pura necessidade. Deve haver, além disso, um fator causal envolvido que determine de um modo regular e não ocasional certo resultado subsequente. Sendo assim, seria natural, nesta perspectiva, todo processo no qual estaria envolvido certo fator causal de caráter formal, isto é, de caráter necessário e suficiente, para que, assim, ocorra determinado resultado. No caso dos processos espontâneos, não há este fator de caráter formal determinante, que atuaria como um princípio causal anterior e regulativo, relativamente aos processos subsequentes que viriam a ocorrer. Há apenas uma confluência ocasional de séries causais necessárias à ocorrência de determinado resultado, mas não suficientes para que assim seja de um modo, por assim dizer, "pré-estabelecido" de acordo com um sistema, ou uma ordem, de equilíbrio natural constante. Para ser considerado como natural, não bastaria, então, a frequência do processo, mas também a regularidade a partir de um mesmo tipo de fonte causal determinante (necessária e suficiente), que se sobreporia às causas de caráter material (meramente necessárias).
} 
espontânea é introduzido por acidente na ordem teleológica" (1945, p. 310). Com efeito, seria justamente por haver na geração natural um princípio formal-final como fator antecedente presidindo de um modo determinado o encadeamento das séries causais material-eficientes, sendo a determinação devida ao processo de reprodução sexuada, que a geração natural diferiria da geração espontânea. Ao contrário da geração natural, a geração espontânea, de uma maneira indeterminada, sempre depende de fatores extrinsecamente relacionados entre si para ser continuamente produzida - por isso, os organismos vivos gerados espontaneamente não se reproduzem de fato.

Desta forma, os organismos vivos gerados espontaneamente conteriam em si certa ordenação teleológica, mas esta ordenação seria incorporada à composição espontânea como um fator concomitante $(\sigma \nu \mu \beta \varepsilon \beta \eta \kappa o ́ \varsigma)$ às causas gerativas, de modo que a causalidade não é teleológica, mas espontânea. Dada a incorporação do $\pi v \varepsilon \tilde{\mu} \mu \alpha$ $(\text { pneuma })^{31}$ na matéria putrefata em processo de cocção por uma causalidade

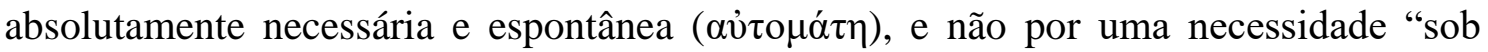

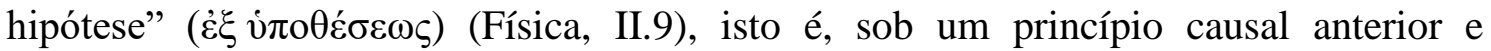
regulativo de caráter formal, segue-se a formação e a ordenação das partes orgânicas que irá compor o organismo vivo gerado espontaneamente, as quais não deixariam de apresentar certas propriedades funcionais, ainda que de uma maneira imperfeita e indeterminada. Com relação ao processo de geração espontânea, Aristóteles declara o seguinte na Geração dos Animais:

Os animais e as plantas nascem na terra e na água porque na terra existe água, na água um sopro vital, e em tudo isto há calor anímico [...]. Por isto, tomam forma rapidamente os seres no momento em que este calor anímico está contido dentro deles. Ele é incorporado quando os líquidos que têm corpo se esquentam, e se formam então como uma bolha de espuma. Pois bem, as diferenças que fazem com que o gênero que está se formando seja mais ou menos valioso reside na envoltura do princípio anímico. Os determinantes disto são tanto os lugares quanto a matéria contida (Geração dos Animais, III.11, 762a18-27). ${ }^{32}$

\footnotetext{
${ }^{31}$ É imprescindível à geração dos seres vivos, seja ela sexual ou espontânea, a presença do $\pi v \varepsilon \tilde{v} \mu \alpha$, no qual está encerrado o calor vital ou anímico. O $\pi v \varepsilon \tilde{\mu} \mu \alpha$ (sopro vital, ar inato) é precisamente o que faz o sêmen fértil (Geração dos Animais, III,11, 762a19-20).

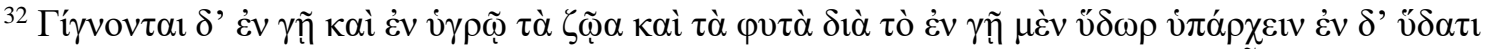

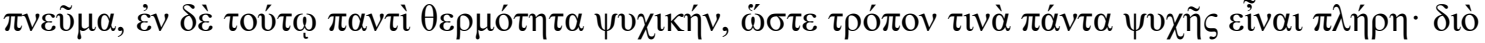



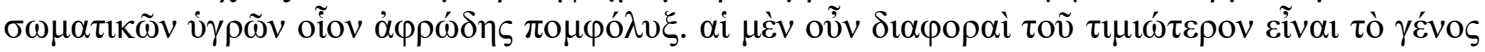

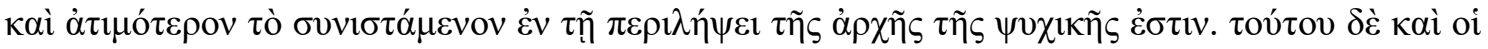




Em conformidade com a passagem supracitada, o processo de geração espontânea poderia ser descrito em outros termos, ou reconstruído, da seguinte maneira: certo montante de terra com água contendo o $\pi v \varepsilon \tilde{u} \mu \alpha$ sofre um aquecimento em função do ar ou da água circundante. Este aquecimento gera uma bolha de ar no entorno deste montante de terra com água, de modo a espessá-la. Concomitantemente, entra em ação o calor vital com certos movimentos formativos do $\pi v \varepsilon v \tilde{\mu} \alpha$ que, no caso, por exemplo, de um testáceo gerado espontaneamente, fará com que se forme, por meio da bolha espessada pelo calor externo do ambiente, uma concha.

No entanto, o que ocasionará a especificidade do organismo vivo - no caso, um testáceo - não será o $\pi v \varepsilon \tilde{u} \mu \alpha$ contendo o calor vital juntamente com movimentos formativos, de modo a atuar de uma maneira definida como um princípio causal regulativo de caráter formal (como seria no caso da reprodução sexuada), mas sim certos fatores contingenciais como o local e o tipo de material presente (Gotthelf, A., 1989, p. 189). Neste processo gerativo, os movimentos formativos do $\pi v \varepsilon \tilde{\mu} \mu \alpha$ não são específicos, ou seja, não são movimentos capazes de transmitir certos caracteres determinantes de dada espécie de organismo vivo previamente constituído, agindo, então, em concomitância com outros fatores causais que convergem ocasionalmente entre si segundo uma necessidade "sem mais" ( $\dot{\alpha} v \alpha ́ \gamma \kappa \eta \dot{\alpha} \pi \lambda \tilde{\omega} \varsigma)$, ou absoluta.

No exemplo do testáceo, o $\pi v \varepsilon v ̃ \mu \alpha$ contido em uma porção de terra e água, sob efeito do calor externo do ambiente, atua como componente teleológico na formação de uma concha. A concha vem a ser desenvolvida em função do $\pi v \varepsilon \tilde{u} \mu \alpha$, mas a sua especificidade não é devida a ele. Ela é devida a fatores extrínsecos ao processo composicional em questão, ou seja, ao mar no qual a porção de terra e água está inserida, juntamente com uma grande quantidade do elemento terroso do meio circundante. São estes fatores, a saber, o mar e o elemento terroso, e não o $\pi v \varepsilon \tilde{\mu} \mu \alpha$, que são responsáveis de uma maneira indeterminada - pelo caráter específico de um testáceo gerado por espontaneidade, através do processo de endurecimento e de solidificação do material ambiente que encerra o corpo que possui vida (Geração dos Animais, III.11, 762a27-32). Assim, a diversidade de tipos de organismos gerados espontaneamente dependerá de fatores tais como o lugar e o tipo de material pertencente ao meio circundante.

Semelhantemente, o processo de geração dos corpos homogêneos se daria a partir de fatores extrinsecamente relacionados entre si, de uma maneira espontânea, de modo a não haver, nesse processo, uma causalidade anterior de tipo formal presidindo as concatenações das séries que regularia as interações materiais, para o estabelecimento de 
determinado arranjo composicional. Entretanto, na medida em que, neste decurso espontâneo, o calor natural do meio circundante, apresentando-se como uma das séries causais concomitantes de natureza material ${ }^{33}$ necessárias à formação do composto homogêneo, desencadeia a atividade de cocção, insere-se, em meio ao processo, uma causalidade de tipo formal. Isto porque, em função da atividade de cocção, certo conjunto de elementos materiais, disposto no meio natural de uma maneira contingente em relação à determinação do composto homogêneo, que até então se apresentava a maneira de agregado, passa a adquirir, agora na mistura, outras propriedades comuns ao todo composicional, distintas daquelas próprias aos elementos tomados separadamente em si mesmos (Geração e Corrupção, I.10, 328b21-22; I.10, 328a28-31).

Por outro lado, diferentemente dos organismos vivos gerados espontaneamente, os corpos homogêneos inanimados, na medida em que, na ocasião do processo formativo, vêm a assumir uma causalidade de tipo formal por meio da atuação do calor natural, não passam a comportar fatores de caráter teleológico-ativos. Tais fatores corresponderiam a certas atividades ou funções vitais que os organismos vivos gerados espontaneamente vêm a apresentar, de uma maneira imperfeita, rudimentar e indeterminada em relação às funções anímicas dos seres vivos gerados de forma sexuada, em função da atuação do calor vital e de certos movimentos específicos ínsitos ao $\pi v \varepsilon \tilde{v} \mu \alpha$.

Enquanto as composições homogêneas inanimadas dependem do calor do Sol, do fogo, para a realização do processo de cocção, as composições homogêneas animadas dependem de outro tipo de calor, a saber, do calor vital ou anímico. O calor vital tem uma natureza distinta daquela do calor natural do fogo (Geração dos Animais. II.3, 736b34 e ss.), possuindo uma particularidade mais complexa. Além do calor em si, o calor vital é caracterizado pela condição de estar imbuído de certos movimentos informacionais ${ }^{34}$, os

\footnotetext{
${ }^{33}$ Uma outra série causal de natureza material corresponderia a certo agregado de elementos materiais que, sob o efeito do processo de cocção por meio da atuação do calor natural, passa a compor certa mistura homogênea.
}

${ }^{34}$ De acordo com Gill, o $\pi v \varepsilon \tilde{v} \mu \alpha$, associado ao calor vital, controla os desenvolvimentos do animal no processo gerativo regulando o calor e o arrefecimento, gerando mudanças nos materiais apropriados, nos tempos apropriados, nos lugares apropriados, e produzindo, assim, partes como a carne e o osso (1997, p. 154; Geração dos Animais, II.6, 743a27-29). Neste sentido, Montgomery Furth afirma: Aristotle's hypothesis is that there is in the semen, not the form itself, nor any portion destined to become the form, but the power of constructing new individuals of that form. The nature of this power is informational (thus it is frequently referred to as a logos, a formula). It is the logos of a pre-determined sequence of physical and chemical formative activities ("movements" and "concoctings") which, given catamenia to work upon, will effectuate a corresponding sequence of changes in the catamenial substrate, each change presupposing those before it, via the postulated physical and chemical mechanisms (as "efficient" or "moving causes") 
quais desempenham um papel determinante na condução formativa das partes não homogêneas, que constituem o organismo vivo como um todo.

Através do calor, as partes homogêneas animadas vêm a ser geradas por meio de um processo de cocção, tal como os compostos homogêneos inanimados, fazendo com que adquiram certas propriedades essenciais. Entretanto, no caso das composições homogêneas do organismo vivo, elas, sob o efeito de determinados movimentos formativos e específicos, se arranjam de uma maneira complexa e ordenada, de modo a comporem, em uma relação intrínseca de interdependência, as partes não homogêneas. Estas, por sua vez, passam a adquirir no organismo vivo outras propriedades essenciais, tais como, por exemplo, as propriedades funcionais de pegar e de apertar da mão (Partes dos Animais, II.1, 646b19-25), que se caracterizariam por uma ordenação de tipo

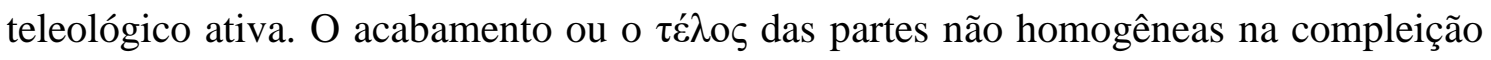
orgânica vem a assumir, então, como propriedades essenciais, não mais aquelas meramente de caráter qualitativas que determinam a natureza das composições homogêneas, mas também outras propriedades, agora, de ordem orgânico-funcionais.

No caso dos corpos homogêneos, há também a decorrência de propriedades emergenciais relativamente às propriedades dos componentes elementares. Contudo, tais propriedades emergentes, na mistura homogênea, limitam-se ao $\tau \dot{\lambda} \lambda o \varsigma$ ou ao acabamento do todo composicional, as quais equivalem estritamente às características qualitativas que estabelecem as especificidades dos corpos homogêneos. Estas propriedades emergentes se manifestariam em função de uma teleologia de tipo passiva, na medida em que se determina certo grau de umidade e de sequidade da mistura homogênea em estado de formação por meio de uma causa formal - que Aristóteles se refere como passiva

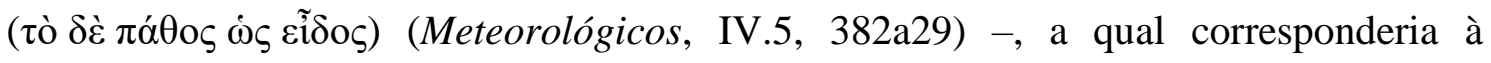
atividade de cocção. Por sua vez, tal grau de umidade e de sequidade, de um modo passivo e na qualidade mesma de potencialidade passiva, irá justamente delimitar, na condição de



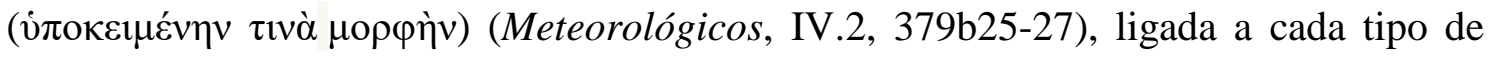
corpo homogêneo.

(1988, p. 117). De uma maneira semelhante, Freudenthal escreve: the movements inhering in blood, semen, etc. embed the program for all the distinctive parts of the animal in question; specifically, by virtue of these movements the semen has an, informational power allowing it to transmit to the offspring the 'program' scribed in the sire's blood (1995, p. 28). 
Rodrigo Romão de Carvalho

Investigador Independente

Referências Bibliográficas

Obras de Aristóteles

Aristóteles (1831). Aristotelis Opera. Bekker, I. (ed.). Academia Regia Borussica, Vols. I-II, Berlim.

Aristóteles (1932). Politics. English Translation by H. Rackham. "Loeb Classical Library". Harvard University Press.

Aristóteles (1935) The Metaphysics, Books 10-14. Oeconomica. Magna Moralia. Trad. by Hugh Tredennick and G. Cyril Armstrong. London: The Loeb Classical Library.

Aristóteles. (1947) The Metaphysics, Books I-IX. Trad. by Hugh Tredennick. London: The Loeb Classical Library.

Aristóteles (1952). Meteorologica. Trad. H. D. P. Lee. London: The Loeb Classical Library.

Aristóteles (1953). Generation of Animals. Trad. A. L. Peck. London: The Loeb Classical Library.

Aristóteles (1955). On Sophistical Refutations; On Coming-to-be and Passing Away; On the Cosmos. Trad. E. S. Foster, and D. J. Furley. London: The Loeb Classical Library.

Aristóteles (1957). On the Soul; Parva Naturalia, On Breath. Trad. de W. S. Hett. London, The Loeb Classical Library.

Aristóteles (1961). Parts of Animals; Movement of Animals; Progression of Animals. Trad. A. L. Peck. London: The Loeb Classical Library.

Aristóteles (1988). Política. Introducción, traducción y notas de M. G. Valdés. Madrid: Editorial Gredos.

Aristóteles (1994). Reproduccíon de los Animales. Trad. e notas de E. Sánchez. Madrid: Biblioteca Clásica Gredos.

Aristóteles (1996). Acerca del Cielo; Meteorológicos. Trad. e notas de M. Candel. Madrid: Biblioteca Clásica Gredos.

Aristóteles (1998). Acerca de la Generación y la Corrupción; Tratados Breves de Historia Natural. Trad. e notas de E. La Croce, e A. B. Pajares. Madri, Biblioteca Clásica Gredos.

Aristóteles (1999). As Partes dos Animais, Livro I. Trad. e comentários de L. Angioni. Cadernos de História e Filosofia da Ciência, 9 (3) (n. especial).

Aristóteles (2000). Partes de los Animales; Marcha de los Animales; Movimiento de los Animales. Trad. e notas de E. J. Sánchez-Escariche, e A. A. Miguel. Madri, Biblioteca Clásica Gredos.

Aristóteles (2002). Física. Trad. e notas de G. R. de Echandía. Madri, Biblioteca ClásicaGredos. Aristóteles (2003). Acerca del Alma. Trad. e notas de T. C. Martínez. Madri, Biblioteca Clásica Gredos.

Aristóteles (2006). Metafísica. Trad. e notas de T. C. Martínez. Madri, Biblioteca Clásica Gredos. Aristóteles (2009). Física I-II. Trad. e comentários de L. Angioni. Campinas: Ed. Unicamp. 


\section{Bibliografia complementar}

Ayala, F. J. (1970) "Teleological explanations in evolutionary biology". Philosophy of Science, Vol. 37, No. 1, pp. 1-15.

Bostock, David. (2006) Space, Time, Matter and Form: Essays on Aristotle's Physics. Oxford: Oxford University Press.

Cohen, S. M. (1996) Aristotle on Nature and Incomplete Substance. New York: Cambridge University Press.

Freudenthal, Gad. (1995) Aristotle's Theory of Material Substance: Heat and pneuma, Form and Soul. Oxford.

Furley, David J. (1983) "The Mechanics of Meteorologica IV: a prolegomenon to biology", in: Moraux and Wiesner (eds.), Zweifelhaftes Im Corpus Aristotelicum (Berlin, de Gruyter), pp. 7393.

Furth, Montgomery. (1987) "Aristotle's biological universe: an overview", in A. Gotthelf e Lennox, J. (eds.). Philosophical Issues in Aristotle's Biology. Cambridge: Cambridge University Press, pp. 21-52.

Gill, Mary L. (1997) "Material Necessity and Meteorology IV 12", in Aristotelische Biologie Intentionen, Methoden, Ergebnisse. Stuttgart: Franz Steiner, pp. 145-161.

Gill, Mary L. (2014) "The Limits of Teleology in Aristotle's Meteorology IV.12", in HOPOS: The Journal of the International Society for the History of Philosophy of Science. Vol. 4, No. 2, pp. 335-350.

Gottheld, Allan. (1987) "Aristotle's conception of final causality", in A. Gotthelf e Lennox, J. Lennox (eds.), Philosophical Issues in Aristotle's Biology. Cambridge: Cambridge University Press, pp. 211-212.

Gottheld, Allan. (1989) “Teleology and spontaneous generation in Aristotle: a discussion”. In: T. Penner e R. Kraut (eds.), Nature Knowlwedge and Virtue (Essays in memory of Joan Kung). Apeiron 22, n. 4 (n. especial), pp.181-193.

Kullmann, W. (1985) "Differents Conceptions of the Final Cause in Aristotle", in A. Gotthelf (ed.), Aristotle on Nature and Living Things. Pittsburgh, Bristol: Mathesis publications, pp.169175.

Lennox, James G. (2014) "Aristotle on the Emergence of Material Complexity: Meteorology IV and Aristotle's Biology", in HOPOS: The Journal of the International Society for the History of Philosophy of Science. Vol. 4, No. 2, pp. 272-305.

Lewis, Frank A. (1994) “Aristotle on the Relation between a Thing and its Matter", in T. Scaltsas, D. Charles e M. L. Gill (eds.), Unity, Identity and Explanation in Aristotle's Metaphysics. Oxford: Clarendon Press, pp. 247-277.

Mansion, A. (1945) Introduction à la Physique Aristotélicienne. 2éme édition revue et augmentée. Louvain: Institut Supérieur de Philosophie,.

Mirus, C. V. (2006) “The Homogeneous Bodies in Meteorology IV 12". In: Ancient Philosophy 26, pp. 45-64.

Owens, J. (1968) "Teleology of Nature in Aristotle". The Monist, Vol. 52, No. 2, Aristotle, pp. 159-173.

Scaltsas, Theodore. (2013) "Mixing the Elements" in A Companion to Aristotle. Ed. Anagnostopoulos, G. Blackwell Publishing. 